\title{
Looking for the Possible Association Between Stress, Presenteeism and Absenteeism Among Croatian Nurses: A Cross-Sectional Study
}

\author{
Hana Brborovic, ${ }^{1,}$ Ognjen Brborovic, ${ }^{2}$ and Jadranka Mustajbegovic ${ }^{1}$ \\ ${ }^{1}$ University of Zagreb, School of Medicine, Andrija Stampar School of Public Health, Department of Environmental and Occupational Health and Sports Medicine, Zagreb, \\ Croatia \\ ${ }^{2}$ University of Zagreb, School of Medicine, Andrija Stampar School of Public Health, Department of Social Medicine and Organization of Health Care, Zagreb, Croatia \\ Corresponding author: Hana Brborovic, MD, PhD, Postdoctoral Research Assistant, University of Zagreb, School of Medicine, Department of Environmental and Occupational \\ Health, Rockefellerova 4,10 000 Zagreb, Croatia. Tel: +385-958000845, E-mail: hana.brborovic@snz.hr
}

Received 2015 November 02; Revised 2016 April 23; Accepted 2016 September 30.

\begin{abstract}
Background: Stress is an important occupational hazard in numerous occupations. The consequences of stress have been associated with a number of health conditions.

Objectives: The aim of this study was to investigate whether nurses' perceived levels of stress are associated to presenteeism and absenteeism.

Materials and Methods: In a cross-sectional study, conducted at a public general hospital in Croatia, medical nurses filled the perceived stress scale (PSS-10) and short-form of the World health organization health and work performance questionnaire (WHO HPQ).

Results: Nurses experiencing absenteeism (26,53\%) had a little higher levels of stress $(X=18.85, S D=7.31)$ when compared to those without absenteeism $(X=17.52, S D=6.63), t(144)=1.037, P=0.301$. Nurses with presenteeism $(15.74 \%)$ had statistically significantly higher levels of stress $(M=21.42, \mathrm{SD}=5.62)$, compared to nurses without presenteeism $(\mathrm{X}=17.35, \mathrm{SD}=6.84), \mathrm{t}(144)=2.47, \mathrm{P}=0.015$. Linear regression $\left(\mathrm{R}^{2}=0.032, \mathrm{P}=0.036\right)$ showed an association between presenteeism and stress $(\mathrm{B}=3.952, \mathrm{~S} . \mathrm{E} .=1.26, \beta=0.069)$. No association was found between absenteeism and stress.
\end{abstract}

Conclusions: Although there is an association between presenteeism and stress, we cannot draw a causal line from this finding.

Keywords: Absenteeism, Nurse, Presenteeism, Stress, Work Performance

\section{Background}

Workplace demands can be perceived as stressful to an individual. As described by Kahn \& Byosiere, job stress relates to physical and behavioral outcomes such as burnout, health complaints, and absenteeism (1). Moreover, these outcomes seem to be interrelated $(2,3)$. Acute stress response allows individuals to mobilize the energy required to fight or overcome stress ("fight or flight"). The shortterm impact of stress does not have to lead to adverse health effects. In fact, short-term stress can have a positive impact. However, the allostatic load theory describes long-term effects of stress as damaging due the wear and tear of the body experiences (4). Stress activates primary stress mediators (cortisol, epinephrine, norepinephrine and dehydroepiandrosterone), which lead to switching from homeostasis in the body to allostasis (Figure 1). The primary stress mediators lead to changes in cardiovascular (catecholamines), metabolic (glucocorticoids), immune (glucocorticoids and catecholamines) systems and brain (glucocorticoids and catecholamines). Consequently, this leads to an increase of waist-hip ratio, blood pressure, cholesterol, glucose and decrease of insulin, immune ca- pacity and glucose tolerance (secondary outcomes) resulting in, cardiovascular disease, severe cognitive decline, diabetes, hypertension and cancer (tertiary outcomes) in the long run (5). With the onset of a disease (acute, episodic or chronic), an employee has an option of taking sick leave (sickness absenteeism) or to come to work despite of the illness (sickness presenteeism). The decision to come to work despite of existing health challenges or to take sick leave is often complex. Even though presenteeism and absenteeism are extreme values on the working scale, similar health, workplace and personal factors affect both of them, but in an opposite manner. As mentioned above, disease is one of the common factors. Workplace factors (perception of the working environment either as a positive or a negative place, daily "must-do tasks", replacement difficulties and tasks that need to be personally covered upon return, management-employee relations, support from peers, job insecurity and culture) and personal reasons (financial reasons, attitudes toward own health, work-life balance and family) often influence the decision of whether to come to work or not (6-13). Moreover, absenteeism and presenteeism are often inter-related. Employees whose health 
problems have not led to absenteeism often show presenteeism. On the other hand, if the employee returns to work while still sick or recovering, the sickness absenteeism can be replaced with sickness presenteeism. Even more so, sickness presenteeism has significant predictive value for future absenteeism (7,14-16).

HOMEOSTASIS

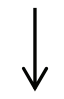

JOB DEMANDS

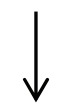

STRESS
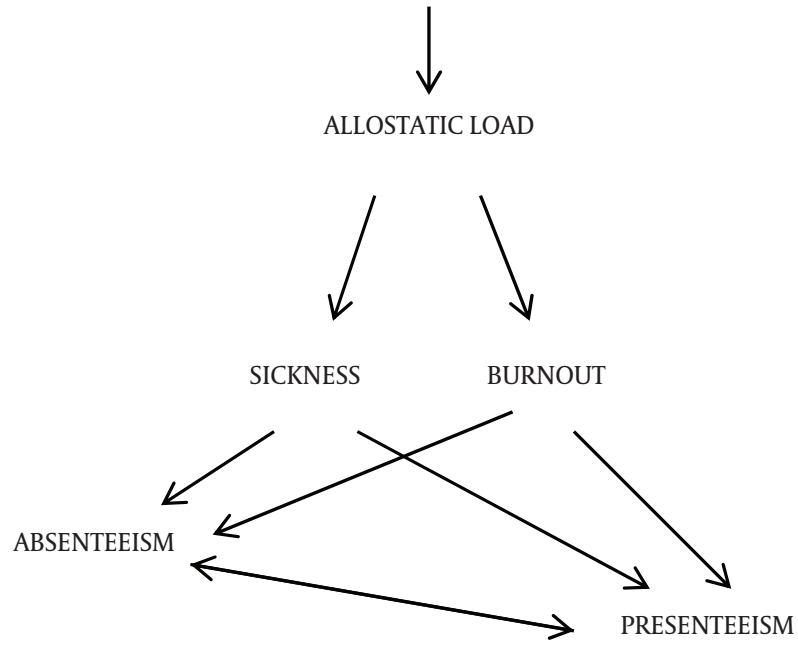

Figure 1. Activation of Primary Stress Mediators Leading to Switching Form Homeostasis in the Body to Allostasis

Absenteeism is defined as any absence from work. Sickness absenteeism is usually registered as sick leave, which sometimes makes it hard to distinguish from just not coming to work $(7,17)$. In Croatia, healthcare and social care sector have the highest sick leave rate. During the year 2013 this rate was $3.11 \%(18,19)$. The frequency of absenteeism can suggest employees' gradual withdrawal behavior, which can result in turnover. Duration of absences is indicative of poor health $(13,20)$. Eriksson et al. found that burnout was associated with long-term sickness absence. They described that events prior to sickness absence can be understood as a process of emotional deprivation, which was described in terms of a flight of stairs with eight steps, which were named "The Burnout Stairs." The course of events preceding sickness absence is a process of emotional deprivation where the individual is gradually emp- tied of the life-giving emotional energy revealed in joy, commitment and empathy (21). Another model, described by Bakker et al. showed that burnout mediated the effects of job demands on absence duration $(13,20)$.

In general, presenteeism is defined as being present at work, but not being able to work in the usual manner (14, 22-24). Employees often work with lower performance (not meeting deadlines, difficulty in concentrating, not being able to think clearly, making mistakes and not being able to carry out the physical requirements of a job), which results in lost productivity $(25,26)$. Presenteeism is even more difficult to measure since there are almost no objective measures. Presenteeism is usually investigated using questionnaires. Therefore, reported presenteeism rates are variable. A Dutch study reported that $70 \%$ of the randomly selected participants reported coming to work sick at least one time during the last year (27). Sickness presenteeism due to acute illness (cold, flu, allergy, etc.) is sometimes more favorable to the employees because they have a choice of whether or not to attend work (8). When it comes to sickness presenteeism due to chronic condition (arthritis, back pain, mental health problems, etc.) employees may need to work despite the impairment $(8,28)$. This type of presenteeism has become a challenging problem in developed countries due to ageing workforce and an increasing number of people with chronic health conditions (29).

\subsection{Nurses}

This study was specifically targeted at nurses, as one of the largest groups of healthcare professionals that play a crucial role in proper healthcare delivery (30). Nurses are more likely to come to work when sick than other occupations $(7,31,32)$. Poor health can affect their performance, which can consequently affect the quality of health care (28). Absenteeism is associated with missed nursing care (33). Nurses and teachers have the highest occupational rates of this type of presenteeism (8). Literature review suggested that demands such as organization of work, financial issues, public criticism, hazards at workplace, interpersonal conflicts, shift-work, professional and intellectual demands, and prolonged fatigue are perceived by nurses as stressful $(34,35)$.

\subsection{Healthcare and Nursing in Croatia}

Croatia has a population of 4284 899. There are 67 hospitals. There are five clinical teaching hospitals, three clinical hospitals, four clinics, 22 general hospitals, and 33 special hospitals. Clinical teaching hospitals and clinical hospitals are state owned. All other hospitals are country owned (36). 
Nurses in Croatia are a very important part of Croatian health care. This professional category accounts for 30000 trained nurses, out of which over 7000 have a college degree. Their activities, education standards, performance requirements, duties and performance quality assessment criteria are stated under the Nursing Act (2003) (37). Most of the nurses work in health care institutions, while a smaller number work in other institutions providing health and social services. Registered nurses can work as a part of a health care team (in primary care settings or in a hospital). Registered nurses having a higher or high education can work as a nursing team leader (38).

\section{Objectives}

It was our aim to investigate whether nurses' perceived levels of stress are associated with presenteeism and absenteeism. Our hypotheses are:

1. Stress is associated to absenteeism

2. Stress is associated to presenteeism

\section{Materials and Methods}

\subsection{Participants}

This was a cross-sectional study, which included medical nurses. The study was conducted at a Public General Hospital in Croatia. The eligibility criteria were set using a convenience sample, which involved the employees' willingness and consent to take part, as well as the geographical proximity to the researchers. The research was anonymous and free willing. A convenience sample of Registered Nurses was recruited. Data were collected during April and May 2012.

\subsection{Data Collection}

Weekly educational nurses' meeting was used to distribute the questionnaire. Questionnaires were distributed in unmarked envelopes along with a consent form by the main investigator. After being filled, the questionnaires and the consent forms were returned in separated sealed and unmarked envelopes. Each respondent returned their envelope to a box, which was found in the nurses' room at each department. Head nurses of the departments collected the boxes and the returned them to the main investigator.

The survey made use of two questionnaires: perceived stress scale (PSS-10) and short -form of the world health organization health and work performance questionnaire (WHO HPQ).

\subsubsection{Perceived Stress Scale}

Perceived Stress Scale (PSS) was designed to measure the stress degree of situations in one's life appraised as stressful (39). The PSS consists of ten questions, which ask the respondent to indicate how often they felt or thought in a certain way in the last month (Appendix 1 in supplementary file). The answers were scaled from 0 to 4 : never was scored 0 , almost never 1 , sometimes 2 , fairly often 3 , and very often 4 . The PSS-10 scores are obtained by reversing the scores on the four positive items, e.g., $0=4,1=3,2$ $=2$, etc. and then summing across all 10 items. Items 4, 5, 7 and 8 are the positively stated items.

\subsubsection{World Health Organization Health and Work Performance Questionnaire}

World health organization hpq questionnaire, first developed by Kessler et al. in 2002, is a self-report instrument designed to estimate the workplace costs of health problems in terms of reduced job performance, sickness absence and work-related accidents/injuries (40). The tool has been shown to have good validity and internal consistency (40). The WHO HPQ short-form consists of 11 questions/statements in which the respondents are asked to describe their work experiences during the seven days of the past four weeks (Appendix 2 in supplementary file). There are two ways of measuring and scoring absenteeism. One relies on the respondent estimating how many hours he/she worked over a four-week period. The other asks the respondent to estimate how many hours he/she worked in the past seven days. The authors of the questionnaire recommend using the four-week estimates when available, as they will tend to smooth out any up or down spikes that might have occurred in a particular week (e.g. a respondent missing several hours of work because of a doctor's appointment). In this research, we used the absolute absenteeism four-week estimate, which is also used in similar research by the authors of the WHO HPQ (41). In this research, we will name the absolute absenteeism 4-Week Estimate just Absenteeism. Presenteeism is conceptualized as a measure of actual performance in relation to possible performance. Unlike absenteeism, a higher score indicates a lower amount of lost performance (42). For the purposes of this research, absolute presenteeism will be referred to as presenteeism.

\subsection{Ethical Considerations}

Since this research was conducted while the first investigator attended postgraduate studies, an approval was obtained from the School's ethical board. An approval was obtained from the hospital board of ethics. After approval from the hospital was obtained, approval from hospital's 
manager was also obtained. Additionally, participants also provided consents.

\subsection{Data Analysis}

All questionnaires were collected and entered to an electronic database and completeness of the data was checked. Questionnaires with missing data were excluded.

For all analyses, statistical significance was set at $\mathrm{P}$ value of $<0.05$. Normality of the data distribution was tested using Kolmogorov-Smirnov Normality Test. Descriptive analysis was used to analyze the participants' age, stress, presenteeism and absenteeism. T-test was used for analysis to compare means of stress. Linear regressions were used to assess the possible association between presenteeism and stress, and between absenteeism and stress. Analysis was performed using SAS version 9.1.3.

\subsection{Validity and Reliability}

Both questionnaires showed adequate internal consistency. The PSS had a Cronbach's $\alpha$ of over 0.80 for three samples (0.84, 0.85 and 0.86, respectively) (39). The HPQ validation studies showed good concordance between measures of self-reported absenteeism and payroll records over a 30-day recall period, with Pearson correlations in the range 0.66 to 0.79 and evidence of some downward bias in mean self-reported absenteeism levels. The HPQ validation studies documented fair to good concordance between measures of self-reported presenteeism and independent measures of work performance based on either supervisor or peer ratings $(40,41,43)$. The WHO HPQ questions were translated to Croatian by one translator and then translated back to English by an independent translator, who was blinded to the original questionnaires. Preliminary research was then performed to estimate questionnaires' validation and standardization. The results are presented in separate research papers, one of which was recently published (44).

\section{Results}

\subsection{Demographic Data}

A total of 194 questionnaires were distributed to all of the nurses, who worked at the hospital at the time. The participating nurses operated in non-surgical, surgical, pediatric, obstetrics, psychiatry departments and intensive care unit (ICU). One hundred and forty-seven questionnaires were returned yielding response rate of $75.77 \%$. Most of participating nursing staff (who wanted to declare their gender) were female $(87.36 \%, \mathrm{~N}=87)$. Most of the respondents worked at non-surgical departments (55/147,
$37.41 \%$ ), while $29.25 \%$ (43/147) worked at the surgical department, $12.24 \%$ (18/147) worked at the obstetric department, $10.88 \%$ at the ICU (16/147), 7.48\% (11/147) at Pediatric department, and $2.72 \%(4 / 147)$ at the psychiatric department. Kolmogorov-Smirnov test reported a non-normal age distribution, $\mathrm{D}(82)=0.165, \mathrm{P}<0.001$. The median for age distribution was $45(\mathrm{SE}=1.03)$, with the minimal value of 22 , and the maximal value of 59 .

\subsection{Results of Perceived Stress Scale}

Kolmogorov-Smirnov test reported the PSS distribution to be normal, $\mathrm{D}(82)=0.058, \mathrm{P}=0.200$. The mean score was $\mathrm{X}=17.09, \mathrm{SD}=6.64$.

\subsection{Absenteeism}

Absenteeism is scored in terms of hours lost per month; a higher score indicates a higher amount of absenteeism. The measure of absolute absenteeism is expressed in raw hours, with a negative lower bound (if the person works more than expected) and an upper bound equal to the number of hours the respondent is expected to work (42). Kolmogorov-Smirnov test reported a nonnormal absenteeism score, $\mathrm{D}(146)=0.134, \mathrm{P}<0.001$. The median for absenteeism distribution was 32 hours (SD = 68.8 ), with minimal value of -184 and the maximal value of 224. This means that an average nurse in our sample did not spend almost a week (32 hours) in the past four weeks. We wanted to further examine nurses with absenteeism, so we used 75th percentile to dichotomize the sample in two subgroups. The nurses in the 75th percentile (64 hours) were place in the Absenteeism group. There were 39 (26.53\%) nurses with absenteeism and 108 without absenteeism. Nurses in the Absenteeism group had a little higher levels of stress $(X=18.85, S D=7.31)$ when compared to those without absenteeism $(X=17.52, S D=6.63)$, but the difference was not statistically significant, $t(144)=1.037, P$ $=0.301$.

\subsection{Presenteeism}

Presenteeism had a lower bound of 0 (total lack of performance during time on the job) and an upper bound of 100 (no lack of performance during time on the job). Kolmogorov-Smirnov test reported a non-normal absenteeism score, $\mathrm{D}(146)=0.2, \mathrm{P}<0,001$. The median for presenteeism distribution was 90 hours $(S D=20.145)$, with minimal value of 0 and maximal value of 100. Lower quartile (25 hours) was used to determine which nurses experienced presenteeism. A total of 20 nurses (15.74\%) experienced presenteeism, while 127 did not. Nurses with presenteeism had significantly higher levels of stress ( $X=21.42$, $\mathrm{SD}=5.62$ ), compared to nurses, who had not experienced 
presenteeism $(X=17.35, \mathrm{SD}=6.84), \mathrm{t}(144)=2.47, \mathrm{P}=0.015$. There were seven nurses, who had experienced both presenteeism and absenteeism.

Linear regression $\left(\mathrm{R}^{2}=0.032, \mathrm{P}=0.036\right)$ showed an association between presenteeism and stress $(\mathrm{B}=3.952$, S.E. $=$ $1.26, \beta=0.069)$. No association was found between absenteeism and stress $(\mathrm{B}=1.057$, S.E. $=1.657, \beta=0.196)$.

\section{Discussion}

The mean PSS (D $(82)=0.058)$, score was similar to the PSS score (18.32) previously described for females of Croatia, in a population study (CroHort) (44). Most of our respondents were females in their forties. According to previous studies, females have consistently higher PSS scores. This was attributed to negatively scored items in the PSS; females often score higher and subjectively experience more stress than males and show a greater worry-disposition (39, 44-49). However, nurses, who had experienced presenteeism, had a statistically significant higher PSS score (21.42). Our findings were similar to that of Musich et al. who found statistically significant higher rates of presenteeism among individuals with high stress (24). A study by MacGregor et al. showed that stressful life events are related to sickness presenteeism in the same extent as they are to sickness absenteeism (14). This was not the case in our sample. Nurses, who had experienced absenteeism, had somewhat higher levels of stress, but the difference was not statistically significant. However, we found it very interesting that in our sample the nurses did not work one week in the four-week frame that was examined. Another interesting finding was that although only $15.74 \%$ nurses reported they had experienced presenteeism, they had statistically significantly higher levels of stress. Research also suggests that sickness presenteeism is a marker of a lifestyle in which symptoms are ignored and medical care is not sought when needed $(50,51)$. These findings suggested that presenteeism could be seen as a risktaking organizational behavior and shows substantial longitudinal relationship with job demand and burnout. Job demand caused higher presenteeism, while depersonalization was an outcome of presenteeism over time. Exhaustion and presenteeism were found to be reciprocal, suggesting that when employees experience exhaustion, they mobilize compensation strategies, which ultimately increase their exhaustion (3).

We were unable to compare our findings with similar papers in which WHO HPQ was used. The reason is that we were able to access only five papers $(40-43,52,53)$. Another reason is that the authors had not used the same questions from the questionnaire and that the results had not been presented in the same manner in all of the papers. We believe that this is something that should be improved for future use. One of the reasons we used this tool was that it measures both presenteeism and absenteeism. This is very important, because there are only a small number of published papers on presenteeism, and even smaller number on presenteeism in nursing. Even more so, a number of papers showed that absenteeism and presenteeism are interrelated $(7,11,14-16)$. However, we encourage the authors of the questionnaire as well as all of the authors using it, to make a consensus on reporting the data. We acknowledge that the convenient sample and relatively small number of participating nurses may have biased the results and that the results might not be generalizable. However, we feel that this convenience sample gives us an insight into an average hospital in Croatia. Another limitation might be that, even though the research was anonymous; the respondents did not feel comfortable to truthfully answer all of the questions. We were not given access to use the actual sick-leave data to compare to absenteeism data. However, HPQ validation studies show good concordance between measures of self-reported absenteeism and payroll records over a 30-day recall period, with Pearson correlations in the range of 0.66 to 0.79 and evidence of some downward bias in mean self-reported absenteeism levels $(40,41,43)$.

We cannot draw generalized conclusions form our results. Our results simply depict a situation we found in our population at a certain moment in time. We found the results interesting and we believe that these results are important findings for occupational health professionals as well as hospital managers, heads of departments and nurses. Future research should aim at a larger group of nurses as well as including other healthcare professionals.

\subsection{Conclusion}

Even though we cannot draw a causal line from this finding, we found the association between presenteeism and stress interesting. We hope that future research will aim at studying larger groups of healthcare professionals with continuous work for designing even more comprehensive absenteeism and presenteeism tools.

\section{Supplementary Material}

Supplementary material(s) is available here.

\section{Footnotes}

Authors' Contribution: Hana Brborovic and Jadranka Mustajbegovic conceived and designed the evaluation. 
Hana Brborovic collected the clinical data. Ognjen $\mathrm{Br}-$ borovic interpreted the clinical data and performed the statistical analysis. Hana Brborovic drafted the manuscript. Hana Brborovic and Ognjen Brborovic revised the manuscript critically for important intellectual content. All authors read and approved the final manuscript.

\section{Declaration of Interest: None declared.}

Funding/Support: The main author was employed by the project 'Health at the workplace and healthy working environment', 108-1080316-0300, financed by the ministry of science, education and sports. All funds for this study were provided by the project.

\section{References}

1. Dollard MF, Winefield AH, Winefield HR. Occupational Stress in the Service Professions. London: Taylor \& Francis; 2003.

2. Davey MM, Cummings G, Newburn-Cook CV, Lo EA. Predictors of nurse absenteeism in hospitals: a systematic review. J Nurs Manag. 2009;17(3):312-30. doi: 10.1111/j.1365-2834.2008.00958.x. [PubMed: 19426368].

3. Demerouti E, Le Blanc PM, Bakker A, Schaufeli WB, Hox J. Present but sick: a three-wave study on job demands, presenteeism and burnout. Career Dev Int. 2009;14(1):50-68.

4. McEwen BS, Stellar E. Stress and the individual. Mechanisms leading to disease. Arch Intern Med. 1993;153(18):2093-101. [PubMed: 8379800].

5. Lupien SJ, Ouellet-Morin I, Hupbach A, Tu MT, Buss C, Walker D, et al. Beyond the stress concept: Allostatic load-a developmental biological and cognitive perspective. In: Cicchetti D, Cohen DJ, editors. Developmental Psychopathology, Developmental Neuroscience. Hoboken, NJ, US: Wiley; 2006. pp. 578-628.

6. Elstad JI, Vabo M. Job stress, sickness absence and sickness presenteeism in Nordic elderly care. Scand JPublic Health. 2008;36(5):467-74. doi: 10.1177/1403494808089557. [PubMed: 18635730].

7. Rantanen I, Tuominen R. Relative magnitude of presenteeism and absenteeism and work-related factors affecting them among health care professionals. Int Arch Occup Environ Health. 2011;84(2):225-30. doi: 10.1007/s00420-010-0604-5. [PubMed: 21140162].

8. Schultz AB, Chen CY, Edington DW. The cost and impact of health conditions on presenteeism to employers: a review of the literature. Pharmacoeconomics. 2009;27(5):365-78. doi: 10.2165/00019053200927050-00002. [PubMed:19586075].

9. Ruez P. Quality and bottom-line can suffer at the hands of the "working sick". Managed Healthcare Executiva. 2004;14(11):46-8.

10. Dew K, Keefe V, Small K. 'Choosing' to work when sick: workplace presenteeism. Soc Sci Med. 2005;60(10):2273-82. doi: 10.1016/j.socscimed.2004.10.022. [PubMed:15748675].

11. Bergstrom G, Bodin L, Hagberg J, Lindh T, Aronsson G, Josephson $M$. Does sickness presenteeism have an impact on future general health?. Int Arch Occup Environ Health. 2009;82(10):1179-90. doi: 10.1007/s00420-009-0433-6. [PubMed: 19504117].

12. Johns G. Contemporary research on absence from work: correlates, causes and consequnces. Int Rev Industrial Organ Psychol. 1997;12:11574.

13. Albion MJ, Fogarty GJ, Machin MA, Patrick J. Predicting absenteeism and turnover intentions in the health professions. Aust Health Rev. 2008;32(2):271-81. [PubMed: 18447814].

14. MacGregor JN, Barton Cunningham J, Caverley N. Factors in absenteeism and presenteeism: Life events and health events. Manag Res News. 2008;31(8):607-15.
15. Schultz AB, Edington DW. Employee health and presenteeism: a systematic review.J Occup Rehabil. 2007;17(3):547-79. doi:10.1007/s10926007-9096-x. [PubMed: 17653835].

16. Burton WN, Conti DJ, Chen CY, Schultz AB, Edington DW. The role of health risk factors and disease on worker productivity.JOccup Environ Med. 1999;41(10):863-77. [PubMed: 10529942].

17. Fitz-Enz J. How to measure human resources management. New York McGraw-Hill; 1984.

18. Hrvatski zavod za zdravstveno osiguranje. Annual Report. [In Cruatian]. Godisnje izvjesce za 2012. godinu. Zagreb: HZZO Direkcija; 2012.

19. Hrvatski zavod za zdravstveno osiguranje. HZZO Year spent 24,000 control sick days. U 2013. [In Cruatian]. godini HZZO proveo 24.000 kontrola bolovanja 2014 7.4. ; 2014.

20. Bakker AB, Demerouti E, deBoer E, Schaufeli WB. Job demands and job resources as predictors of absence duration and frequency. J Vocat Behav. 2003;62:341-56.

21. Eriksson UB, Engstrom LG, Starrin B, Janson S. Insecure social relations at work and long-term sickness absence due to burnout and other mental diagnoses. Work. 2011;38(4):319-27. doi: 10.3233/WOR2011-1135. [PubMed: 21508521].

22. Caverley N, Cunningham JB, MacGregor JN. Sickness presenteeism, sickness absenteeism, and health following restructuring in a public service organization. J Manag Stud. 2007;44(2):304-19.

23. Hemp P. Presenteeism: at work-but out of it. Harv Bus Rev. 2004;82(10):49-58. [PubMed:15559575] 155.

24. Musich S, Hook D, Baaner S, Edington DW. The association of two productivity measures with health risks and medical conditions in an Australian employee population. Am J Health Promot. 2006;20(5):35363. [PubMed: 16706007].

25. Sanderson K, Cocker F. Presenteeism-implications and health risks. Aust Fam Physician. 2013;42(4):172-5. [PubMed: 23550237].

26. Lerner D, Amick B3, Rogers WH, Malspeis S, Bungay K, Cynn D. The Work Limitations Questionnaire. Med Care. 2001;39(1):72-85 [PubMed: 11176545].

27. Hansen $\mathrm{CD}$, Andersen JH. Going ill to work-what personal circumstances, attitudes and work-related factors are associated with sickness presenteeism?. Soc Sci Med. 2008;67(6):956-64. doi 10.1016/j.socscimed.2008.05.022. [PubMed: 18571821].

28. Letvak SA, Ruhm CJ, Gupta SN. Nurses' presenteeism and its effects on self-reported quality of care and costs. Am J Nurs. 2012;112(2):30-8. doi 10.1097/01.NAJ.0000411176.15696.f9. [PubMed: 22261652] quiz 48, 39.

29. Cancelliere C, Cassidy JD, Ammendolia C, Cote P. Are workplace health promotion programs effective at improving presenteeism in workers? A systematic review and best evidence synthesis of the literature. BMC Public Health. 2011;11:395. doi: 10.1186/1471-2458-11-395. [PubMed: 21615940].

30. Gartner FR, Nieuwenhuijsen K, van Dijk FJ, Sluiter JK. The impact of common mental disorders on the work functioning of nurses and allied health professionals: a systematic review. Int J Nurs Stud. 2010;47(8):1047-61. doi: 10.1016/j.ijnurstu.2010.03.013. [PubMed: 20444449].

31. McKevitt C, Morgan M, Dundas R, Holland WW. Sickness absence and 'working through' illness: a comparison of two professional groups. J Public Health Med. 1997;19(3):295-300. [PubMed: 9347453]

32. Aronsson G, Gustafsson K, Dallner M. Sick but yet at work. An empirical study of sickness presenteeism. J Epidemiol Community Health 2000;54(7):502-9. [PubMed: 10846192]

33. Kalisch BJ, Tschannen D, Lee $H$, Friese CR. Hospital variation in missed nursing care. Am J Med Qual. 2011;26(4):291-9. doi 10.1177/1062860610395929. [PubMed: 21642601].

34. Golubic R, Milosevic M, Knezevic B, Mustajbegovic J. Work-related stress, education and work ability among hospital nurses. J Adv Nurs. 2009;65(10):2056-66. doi: 10.1111/j.1365-2648.2009.05057.x. [PubMed: 19627386]. 
35. Sluiter JK, de Croon EM, Meijman TF, Frings-Dresen MH. Need for recovery from work related fatigue and its role in the development and prediction of subjective health complaints. Occup Environ Med. 2003;60 Suppl 1:i62-70. [PubMed: 12782749].

36. Ostroski L. Statistical yearbook of the Republic of Croatia 2012. Zagreb: Croatian Bureau of Statistics; 2012.

37. Croatian Government . Nursing Act, Narodne novine. ; 2003.

38. Kalauz S, Orlic-Sumic M, Simunec D. Nursing in Croatia: past, present, and future. Croat Med J. 2008;49(3):298-306. [PubMed: 18581608].

39. Cohen S, Kamarck T, Mermelstein R. A global measure of perceived stress. J Health Soc Behav. 1983;24(4):385-96. [PubMed: 6668417].

40. Kessler RC, Barber C, Beck A, Berglund P, Cleary PD, McKenas D, et al. The World Health Organization Health and Work Performance Questionnaire (HPQ). J Occup Environ Med. 2003;45(2):156-74. [PubMed: 12625231].

41. Kessler RC, Berglund PA, Coulouvrat C, Hajak G, Roth T, Shahly V, et al. Insomnia and the performance of US workers: results from the America insomnia survey. Sleep. 2011;34(9):1161-71. doi: 10.5665/SLEEP.1230. [PubMed: 21886353].

42. Kessler RC, Petukhova M, McInnes K, Ustün TB. Content and scoring rules for the WHO HPQ absenteeism and presenteeism questions. Boston: Harvard Medical School; 2012.

43. Kessler RC, Ames M, Hymel PA, Loeppke R, McKenas DK, Richling DE, et al. Using the World Health Organization Health and Work Performance Questionnaire (HPQ) to evaluate the indirect workplace costs of illness. J Occup Environ Med. 2004;46(6 Suppl):S23-37. [PubMed: 15194893].

44. Fazlic H, Brborovic O, Rukavina TV, Fister K, Milosevic M, Mustajbegovic J. Characteristics of people with the perceived stress in croatia: the CroHort study. Coll Antropol. 2012;36 Suppl 1:165-9. [PubMed: 22338766].

45. Nielsen L, Curtis T, Kristensen TS, Rod Nielsen N. What characterizes persons with high levels of perceived stress in Denmark? A national representative study. Scand J Public Health. 2008;36(4):369-79. doi: 10.1177/1403494807088456. [PubMed: 18539691].

46. Gitchel WD, Roessler RT, Turner RC. Gender effect according to item directionality on the perceived stress scale for adults with multiple sclerosis. Rehabil Counsel Bull. 2011;55(1):20-8.

47. Hewitt PL, Flett GL, Mosher SW. The Perceived Stress Scale: Factor structure and relation to depression symptoms in a psychiatric sample. J Psychopathol Behav Assess. 1992;14(3):247-57.

48. Schulz P, Schlotz W, Wolf J, Wust S. Gender differences in stressrelated variables: the influence of worry-disposition. J Differ Diagnos Psychol. 2002;23(3):305-26.

49. Ross CE, Wu C. The links between education and health. Am Sociol Rev. 1995;1:719-45.

50. Kristensen TS. Sickness absence and work strain among Danish slaughterhouse workers: an analysis of absence from work regarded as coping behaviour. Soc Sci Med. 1991;32(1):15-27. [PubMed: 2008617].

51. Taloyan M, Aronsson G, Leineweber C, Magnusson Hanson L, Alexanderson K, Westerlund H. Sickness presenteeism predicts suboptimal self-rated health and sickness absence: a nationally representative study of the Swedish working population. PLoS One. 2012;7(9):e44721. doi: 10.1371/journal.pone.0044721. [PubMed: 22984547].

52. Cocker F, Martin A, Scott J, Venn A, Sanderson K. Psychological distress, related work attendance, and productivity loss in smallto-medium enterprise owner/managers. Int J Environ Res Public Health. 2013;10(10):5062-82. doi: 10.3390/ijerph10105062. [PubMed: 24132134].

53. Wang PS, Beck A, Berglund P, Leutzinger JA, Pronk N, Richling D, et al. Chronic medical conditions and work performance in the health and work performance questionnaire calibration surveys. J Occup Environ Med. 2003;45(12):1303-11. doi: 10.1097/01.jom.0000100200.90573.df. [PubMed: 14665817]. 